\title{
Introducing climate variability in energy systems modelling
}

\author{
Filipa Amorim ${ }^{\text {a, c, * , Sofia G. Simoes }}{ }^{\text {a, c }}$, Gildas Siggini ${ }^{\text {b }}$, Edi Assoumou ${ }^{\text {b }}$ \\ ${ }^{\text {a } C E N S E ~-~ C e n t r e ~ f o r ~ E n v i r o n m e n t a l ~ a n d ~ S u s t a i n a b i l i t y ~ R e s e a r c h ~ E n e r g y ~ a n d ~ C l i m a t e, ~ N O V A ~ S c h o o l ~ o f ~ S c i e n c e ~ a n d ~ T e c h n o l o g y, ~ N O V A ~ U n i v e r s i t y ~ L i s b o n, ~}$ \\ Portugal \\ ${ }^{\mathrm{b}}$ Centre de Mathématiques Appliquées (CMA), MINES ParisTech, Sophia Antipolis, France \\ ${ }^{\mathrm{c}}$ LNEG - National Laboratory for Energy and Geology, Portugal
}

\section{A R T I C L E I N F O}

\section{Article history:}

Received 13 December 2019

Received in revised form

5 June 2020

Accepted 7 June 2020

Available online 14 June 2020

\section{Keywords:}

Climate/energy modeling

Climate variability

Spatial and temporal disaggregation

Climate change and adaptation

Renewable power

\begin{abstract}
A B S T R A C T
This paper presents the ongoing research within Clim2Power project Portuguese case study. Its main goal (as a first step) is to show the relevance of using a highly detailed spatial and temporal modeling tool of the Portuguese electricity system in order to be able to adequately capture climate variability in the planning of the system up to 2050. To do so, we consider seasonal and intraday hydro, wind and solar resources variability in a large TIMES energy system model, in the eTIMES_PT model. Existing hydro, wind and thermal powerplants are modelled individually, whereas new plants are modelled at municipality level. The importance of introducing climate variability is assessed by modeling six scenarios: a reference case and both "humid" and "dry" hydropower scenarios. Each of these is also modelled with $\mathrm{CO}_{2}$ emissions cap by 2050. Results show that hydropower electricity generation variations are within range of those referred in literature by other authors. However, in this work, we are able to capture higher variations within seasons and time of day. Also, the analysis enables to account for the combined variability of hydro, PV and wind resources. This variability will subsequently consider data from seasonal forecasts and climate projections.
\end{abstract}

() 2020 Elsevier Ltd. All rights reserved.

\section{Introduction}

The transition from fossil to renewable energy sources (RES) is seen as a precondition for preventing major climate disruption within the next decades. This trajectory is in place: renewable electricity is expected to play a major role by providing nearly $30 \%$ of electricity demand, compared to $24 \%$ in 2017; also renewables will meet more than $70 \%$ of global electricity generation growth in 2023, led by solar PV, wind, hydro and bioenergy [1]. Yet, the adoption of RES technologies may be counter productive if planning does not consider possible future climate impacts in the operation of the power system, as renewable electricity supply and demand are both strongly influenced by weather conditions, climate variability and climate change; in addition, the climate adaptation options can greatly influence the demand side.

Clim2Power (C2P) project is a research project aimed at climateproofing the current European electricity systems operation and planning, ensuring that energy and power models respond to

\footnotetext{
* Corresponding author. LNEG - National Laboratory for Energy and Geology, Portugal.

E-mail address: filipa.amorim@lneg.pt (F. Amorim).
}

climate variability [24]. The project allows the inclusion of state-ofthe art seasonal weather forecasts into the planning of the operation of the power systems as well as long-term energy/electricity systems planning. Also, C2P builds a bridge between complex scientific model-based knowledge and targeted, useable information for end users within Climate, Environment, Energy and Water communities by delivering a tailored climate service webapplication co-developed with final users. Two levels of climate services are being produced: i) operational information mainly targeted for power companies, namely seasonal weather decisionsupport information on the optimal operation of hydro, wind and solar power plants and on the implications of operational schedules on the whole power system for the next season; ii) investment decision information, mainly for policy makers with a focus on long-term analysis.

C2P goes beyond state of the art by applying state-of-the-art seasonal climate data, adopting an holistic approach of the power and the hydrological system, including concurrent water uses, availability of other intermittent RES and impacts of climate in electricity demand, evaluating the impact on cost competitiveness of different electricity generation portfolios, and co-developing the climate web-service with final users to be made available for free. 
Fig. 1 illustrates the C2P pipeline of different models, an analytical approach that translates the climate data (seasonal forecasts and long-term climate projections) into indicators useful for end-users. Climate data is input to hydrological models, wind and PV simulation tools and variations of electricity, space heating and cooling changes in demand. Each of the results is in turn input in an energy system model to deliver the output indicators. More details on the methodologies developed within the $\mathrm{C} 2 \mathrm{P}$ project can be found in [24].

The C2P climate service covers the whole interconnected European electric system [24] complemented with four case-studies reflecting various EU contexts (Portugal, Sweden, France and Germany-Austria) regarding climate, hydrology, socio-economic settings, electricity generation portfolios and energy markets. In each case study, wind, solar and hydro power generation as well as the demand are simulated from climate data and their effect on the energy system is analysed. Since the effect of climate is expected to have a major impact on hydropower: a special attention is paid to the modeling of three river basins: the Douro river basin in Portugal, the Lule älv river basin in Sweden, and the Danube river basin in Germany-Austria.

This paper presents the ongoing research within the C2P Portuguese case study. Its main goal is an initial step to show the relevance of using a highly detailed spatial and temporal modeling tool of the Portuguese electricity system, in order to be able to adequatly capture climate variability in the planning of the future in the long-term. As an initial step, in this paper we do not yet consider the use of different scenarios based on climate variables data derived scenarios prepared within the project (Climate Data column referred in Fig. 1), but we have focused on the technical possibility of the energy modeling strategies to cover increased spatial and temporal disaggregation and, with this, be able to capture further temporal and spatial variability (Input Indicators and Output Indicators referred in Fig. 1). The focus in the Portuguese case study is carefully chosen because of the significant role renewables currently play in the electricity system (with RES generation ranging between $46 \%$ and $57 \%$ in a dry and a humid year), including a significant presence of variable RES generation (of approx. 25\% in 2017) [2] which has enabled the use of existing historial data to desing the scenarios.
The paper is organized as follows: section 1 reviews the literature, while section 2 reviews the method here used to combine increased spatial and temporal resolution, describing the eTIMES_PT model being developed. After that, section 3 presents and discusses the preliminary long-term output indicators (installed capacity, electricity generation, $\mathrm{CO}_{2}$ emissions, etc). Finally, section 4 concludes and points to where our future research work is heading.

\section{Literature review}

[3] review how climate change impacts research has recently progressed, looking at both supply and demand sides of electric power systems (e.g.: temperature-sensitive demand estimation, plant-level effects of cooling water/ambient air temperature increase; supply vulnerabilities due to decreased water availability for power generation, localized impact of climate variations on wind resources). These authors identify gaps in the literature to which this paper contributes, namely, research on system-wide impact of climate on renewables and thermal power generation, as well as long-term combined climate/energy modeling at a national or regional level. Some of these gaps are further analysed by Ref. [4] through a systematic review of the literature agreeing that in the energy systems optimization models there is the need to consider temporal and spatial resolution to assess climate impacts and incorporate multiple climate change impacts on demand and supply side at the same time.

Particularly, in order to account for the impacts of changing patterns of climate variables, within one or multiple sub-regions, several authors have looked into individual resources impacts in electricity generation, such as wind - [5] analyse present and future potential of offshore wind power in northern Europe based on a downscaled global climate data runs [6]; further discuss the impact of wind climatology on the planning of the European wind power sector -; or solar [7] analyse the future of solar PV outputs in Europe using EUROCORDEX ensembles of high resolution climate data projections. Other authors have gone further to analyse the climate change impacts simultaneously on more than one resource, namely, variable renewables (wind and $\mathrm{PV}$ ) in the EU power system in 2030 with the well known ambitious decarbonization goals [8]

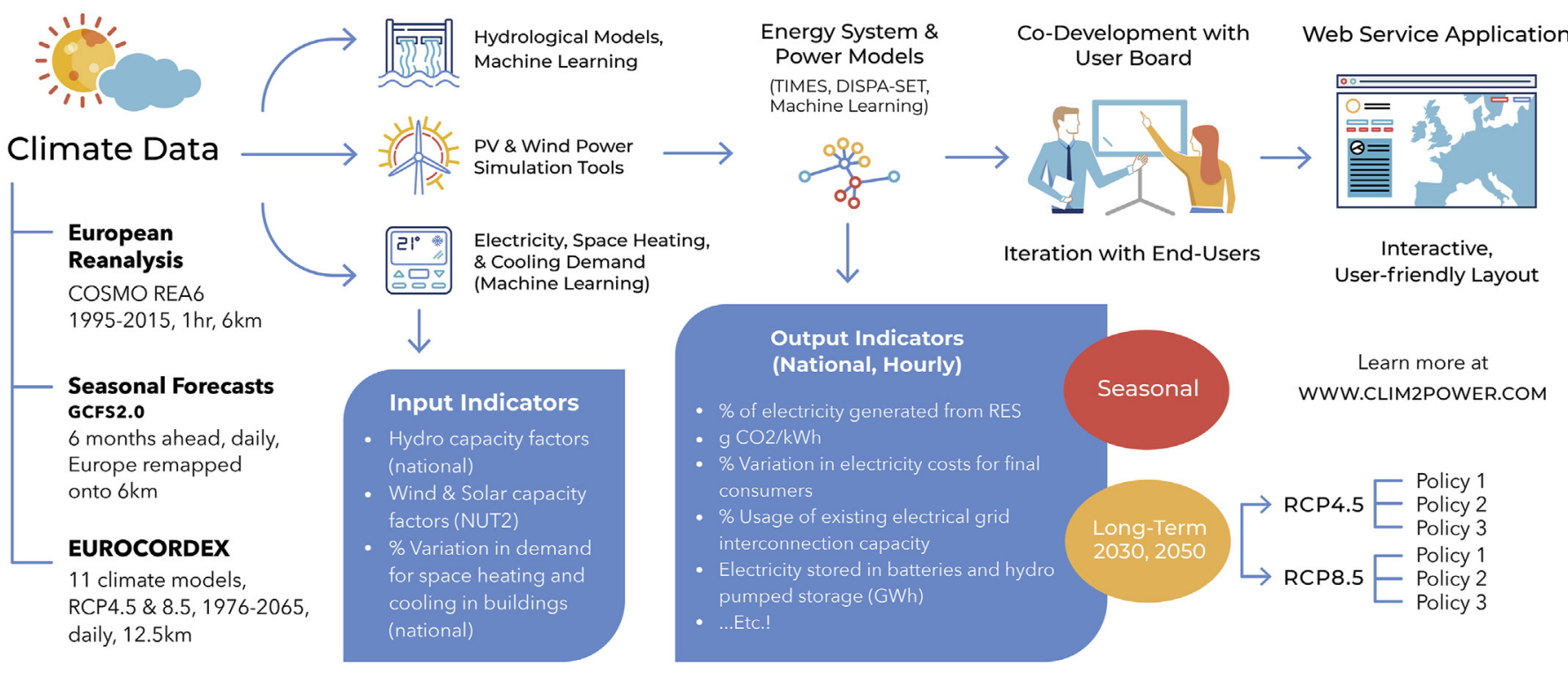

Fig. 1. Overview of the C2P approach. 
or the impact on hydropower and the whole mix from decreasing water availability in 2050 [9].

Worth to mention that [8] perform a thorough methodological review of modeling strategies to integrate short term variations of the power system into integrated energy system models. With this respect, some recent examples of electricity systems planning studies using, in particular, disaggregated TIMES family energy modeling tools with higher temporal resolution [10] or [11]. [12] present a literature review on the strategies to integrate spatial and temporal resolution in energy systems models and argue that although the several identified studies provided valuable insights into the research area, these did not consider any spatial resolution. This type of anaylis has been pursued by others, such as [13] or [9], who have zoomed in the spatial distribution of means of generation.

To the authors' knowledge, so far, none of the published research work has yet presented modeling strategies that enable the assessment of both spatial and temporal variation of variable renewable energy sources as dealt with by models used for climate and energy policy support (as is the case of TIMES models). This is fundamental to better consider the impacts of changing weather/ climate patterns in the future of energy/electricity systems. To this end, within the C2P Portuguese case study, the authors developed an energy modeling tool, the eTIMES_PT model, that allows the use of downscaled climate data (seasonal forecasts and long-term projections) to account for their cascade impacts on variable RES electricity generation (hydro, wind and solar), as well as temperature dependent electricity demand, to translate them into the possible future mixes of electricity generation, installed capacities and GHG emissions. In particular the Portuguese case study is very interesting as the system is characterized by a high share of RES - in 2016 RES represented a $67 \%$ of installed capacity, from which $25 \%$ intermittent.

\section{Methods and assumptions}

To highlight the relevance of using a highly detailed (temporal, spatial and technolgycal) electricity system modeling tool to adequately capture climate variability in the planning of the electricity/energy system, we have built a disaggregated TIMES energy system model for Portugal from 2016 till 2060 and we assess the role of varying the future hydropower availability in the whole power system, especially regarding wind and solar deployment. Our results are compared with those found using another TIMES model which presents lower spatial and temporal resolution for hydro power generation [9], as well as the results for the electric power sector of the National Roadmap for a Carbon Neutral Economy in 2050 [14].

\subsection{The eTIMES_PT model}

The work herein described uses the TIMES (The Integrated MARKAL-EFOM) model family for Portugal. TIMES is a dynamic linear optimization model generator developed by ETSAP (Energy Technology Systems Analysis Programme) from International Energy Agency. The generic structure of the model may be adapted to simulate local, regional or multi-regional energy systems [15]. Based on a technology database (e.g. production capacity, efficiency, all sorts of costs, namely investment, fixed and variable operation and maintenance, fuels) and external constraints (such as GHG emissions caps, fossil fuel import prices or renewable energy technology development potential), TIMES is used to compute the energy supply/demand equilibrium under conditions of perfect foresight. The ultimate goal of a TIMES model is to satisfy energy services demand at the minimum total system cost, making simultaneous decisions about equipment investment and operation, primary energy supply and energy trade [15].

The model developed for this work is the eTIMES_PT model of the Portuguese (mainland) electricity system. At this stage, the model represents Portugal alone, not considering yet electricity exchanges within the Iberian power market or the EU. The models runs from 2016 up to 2050, with results every 1 or 5 years.

The intra annual time resolution of the eTIMES_PT is of 64 time slices, which represent 3 h' time slots for sequential intraday periods, from P1 to P8 (i.e. from 0 h to $3 h, 3 \mathrm{~h}-6 \mathrm{~h}, 6 \mathrm{~h}-9 \mathrm{~h}, 9 \mathrm{~h}-12 \mathrm{~h}$, 12 h-15 h, 15 h-18 h, 18 h-21 h, 21 h-0h), for 2 typical days (weekdays, represented with "B", and weekends, representd with "E") and each for the 4 seasons of the year (DJF for December, January, February; MAM for March, April, May; JJA for June, July, August; and SON for September, October, December). This resolution was found to be convenient according to the literature [16]. have presented an analysis of intraday optimization process and found that for the long-term 3 hourly resolution was deemed to be enough to cover the characteristics of diurnal demand and variable RES fluctuations. In the eTIMES_PT model, in order to account for increased variability of load patterns, it was decided also to model separately in each season, both the weekdays and weekends. The spatial resolution of the eTIMES_PT is atomistically composed by each existing power plant in the Portuguese electricity system, except for the small power generating units, particularly considering solar PV technology based units, which are modelled per technology type - centralized and decentralised.

The model is supported by a detailed database based on the very recently published national modeling studies by Ref. [14,17], with the following main exogenous inputs used: (1) electricity demand evolution; (2) characteristics of the existing and future electricity generation technologies, such as efficiency, stock, availability, investment costs, operation and maintenance costs, and discount rate; (3) present and future sources of primary energy supply and their potentials; and (4) policy constraints and assumptions. Below, Table 1 summarizes the installed capacity of the Portuguese (mainland) electricity system in 2016 and 2017 [2,18], as well as the maximum potentials to explore the available resources in the country in 2030 and in 2050 [14,17]. Additionally, Table 2 provides a status of the evolution of the main technologies investment costs [14,17].

The electricity demand inputs into eTIMES_PT are based in historic values for 2016 and 2017, of 164.9 PJ and 166.0 PJ, respectively, which is considered to grow up to $183.4 \mathrm{PJ}$ in 2030 (0.8/year between 2017 and 2030) and $210.1 \mathrm{PJ}$ in 2050 (0.7/year between 2030 and 2050). This evolution is similar to the "out-of-track" (or Fora de Pista) scenario analysed in the study of the National

Table 1

Generation capacity of the Portuguese (mainland) electricity system in 2016 (REN, 2018) [18], and maximum deployment potentials in 2030 and 2050 [17].

\begin{tabular}{|c|c|c|c|c|c|c|}
\hline \multirow[t]{2}{*}{ GW } & \multicolumn{4}{|c|}{ Historic Values } & \multicolumn{2}{|c|}{$\begin{array}{l}\text { Future } \\
\text { potential }\end{array}$} \\
\hline & 2016 & & 2017 & & 2030 & 2050 \\
\hline Total & 19.8 & $\%$ & 20.1 & $\%$ & & \\
\hline Hydro & 6.945 & 35 & 7.193 & 36 & 9.834 & 9.834 \\
\hline Wind Onshore & 5.07 & 26 & 5.09 & 25 & 12.8 & 13.2 \\
\hline Wind Offshore & 0 & & 0 & & 34 & 40 \\
\hline Solar Centralised & 0.52 & 2.6 & 0.585 & 3 & 6 & 12 \\
\hline Solar Decentralised & 0.225 & 1.1 & 0.277 & 1.4 & 2.5 & 13 \\
\hline Biomass, Biogas, Waste & 0.613 & 3 & 0.624 & 4 & - & - \\
\hline Coal & 1.756 & 9 & 1.756 & 9 & 0 & 0 \\
\hline Natural Gas & 4.636 & 23 & 4.607 & 23 & - & - \\
\hline Others & 0.06 & 0.3 & 0.04 & 0.2 & - & - \\
\hline Wave & 0 & & 0 & & 5 & 7.7 \\
\hline
\end{tabular}


Table 2

Technology investment costs evolution in $\operatorname{Euros}_{2016} / \mathrm{MW}$.

\begin{tabular}{llll}
\hline Technology & 2020 & 2030 & 2050 \\
\hline Wind Onshore & 1041 & 1020 & 989 \\
Wind Offshore & 3475 & 2692 & 2100 \\
Solar PV Roof & 1062 & 1013 & 937 \\
Solar PV Plant & 781 & 745 & 690 \\
Hydro Run of River & 1289 & 1190 & 1075 \\
Biomass Standard & 2303 & 2303 & 2303 \\
Biogas & 3431 & 3363 & 3230 \\
Municipal Waste & 3018 & 2566 & 2465 \\
CCGT conventional & 1051 & 1051 & 1051 \\
CCGT advanced & - & 677 & 677 \\
Waves & 3838 & 3159 & 2074 \\
\hline
\end{tabular}

Roadmap for Carbon Neutrality in 2050 [14,17]. All assumptions, as far as possible, have also been considered identical to the ones in this study, in particular, the referred socio-economic scenario Fora de Pista. Coal power plants are phased out in 2030, following current national energy plans and end-of-life. In this analysis all variable RES resources are also available to generate electricity that can cover peak demand hours. Concentrated solar and nuclear power plants are excluded from the analysis. $\mathrm{CO}_{2}$ emissions are taxed by the price of the EU-ETS of $20 € /$ ton.

\subsubsection{Spatial disaggregation of existing RES technologies (hydro,} solar, wind)

The eTIMES_PT model includes a number of 'regions' relevant to translate the diversity of features of RES electricity technologies and their potential to explore the future of hydrologic available resources for electricity generation, as well as of solar radiation and wind. Also, the model captures the day-time variability within intervals of $3 \mathrm{~h}$. In the hydropower case, the model details all existing plants in the national electricity system, which are characterised as being either run-of-river (RoR) or reservoir (Dam) and each of their maximum capacity factors is identified, including for 14 of these located in the Portuguese Douro river catchment (see Fig. 2). In the Portuguese Douro catchment, there is a total of 66 hydro power plants, out of which 14 major ones (each with an installed capacity above $15 \mathrm{MW}$ ) represent more the $90 \%$ of total installed capacity in the Douro catchment and nearly $33 \%$ of total installed hydro power capacity in the Portuguese electricity system.

For windpower, 231 existing onshore wind farms (by 2016) are characterised for now with one average national maximum capacity factor. In the case of solar PV, two types of plants are considered, one PV centralised and another PV decentralised rooftop application, each characterised by one single average national maximum capacity factor as reference. above.

\subsection{Scenarios analysed with increased RES (hydro, wind and solar) spatial and temporal resolution}

In this work, the impact of two contrasting future hydro power availability scenarios are assessed and compared with the reference scenario (r): one "humid"(h) and another "dry" (d). The "humid scenario" considers that the maximum capacity factors in each time-slice within the period from 2018 to 2050 is the same as observed in an historic year with very high hydro generation (i.e. $2016 \mathrm{IPH}=1.32$ ); and the "dry scenario" considers the same criteria for the maximum capacity factors in each time-slice within the analysed future period for one historic year with very low hydro generation (i.e. $2017 \mathrm{IPH}=0.47$ ). The "reference scenario" assumes the maximum capacity factors in each time-slice in that period as an average of all observed capacity factors, per power plant, on an hourly basis for a set of years ranging from 2004 to 2017. These maximum capacity factors per time-slice have been calculated based on the hourly data gently provided by the EDP for the Douro river basin major power plants [19] and on hourly hydro power generation data for the whole of Portugal for the remaining [20]. Moreover, each scenario is modelled with and without a $\mathrm{CO}_{2}$ cap in

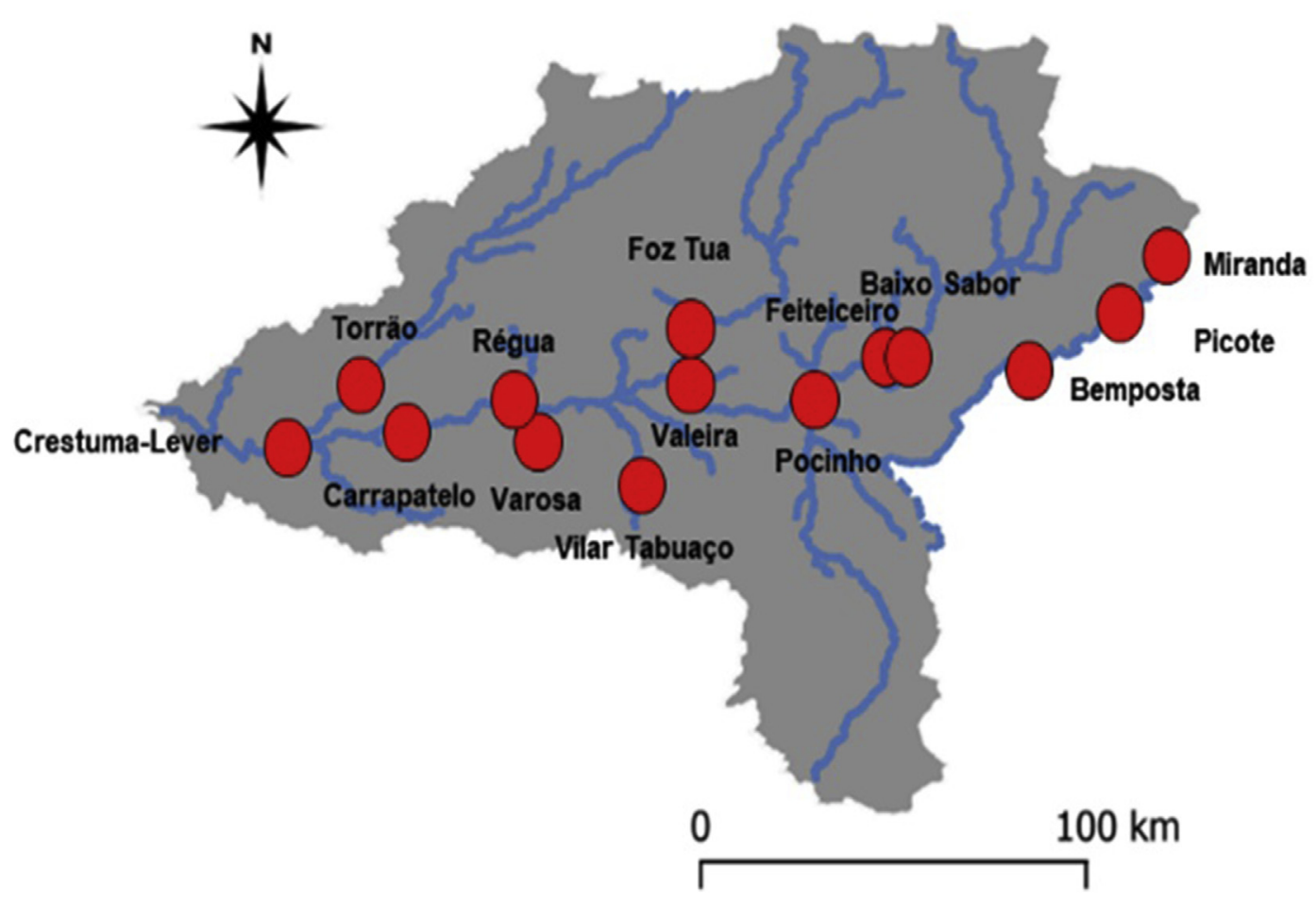

Fig. 2. Hydropower plants located at Douro river and its tributaries in the Douro catchment. 
2050 of $40 \%$ from 1990 values in order to assess the flexibility of the system to further environmental constraints in each of the scenarios (r_c, d_c, h_c, respetively for reference, dry and humid capacity factors).

Fig. 3 illustrates the diversity of the annual average of the maximum capacity factors for the 14 hydro power generation hydro power plants in Douro river basin and for 2 synthetic categories of the remaining hydro power plants in the country depending if these are run-of-river or reservoir. The final column illustrated on the right side of Fig. 3 represents a simple average of overall hydro power generation for the considered scenarios "reference (r)", "dry (d)" and "humid (h)". In these six scenarios, on average, the hydro maximum capacity factor is $20 \%, 12 \%$ and $31 \%$, in the case of "reference", "dry" and "humid" scenarios respectively.

The diversity of hydro power generation modeling structure embodied in the eTIMES_PT model can be described in Fig. 3 as follows: for hydroplant \#5 the maximum capacity factor on an annual basis in the "reference scenario" is $20 \%$ and equal to that of the "dry scenario", while in the humid scenario this hydroplant \#5 maximum capacity factor is on an annual basis $52 \%$. Similarly, for hydroplant \#4 the maximum capacity factor on an annual basis in the "reference scenario" is nearly $20 \%$, in "dry scenario" it is $10 \%$ and in the "humid scenario" nearly $37 \%$.

This figure then serves to illustrate that the original departure point of these hydro power plants have different characteristics, whose differences will be further increased in future studies, when distint climate trends of hydro resource in each of these hydro units will be able to influence per se the scenario behaviour. This higher granularity will hence allow to capture further the granularity of this system.

For both variable RES technologies - wind and solar PV -, the maximum potential of installed capacity is limited at a national level as depicted in Table 1 and considered in the National Roadmap Carbon Neutrality in 2050 by Ref. [14,17]. However, in this work, the potential has been further distributed per municipality, according to the methodology presented in Refs. [21] for PV and, considering the maximum potential will be fulfilled by repowering the current municipal areas where windpower plants are currently located, for wind. Moreover, the variation considered for wind and solar PV, for the period from 2018 to 2050 , have been those that historically are approximate to an average annual factor, as shown in Fig. 4 below, which means for solar PV, year 2015, and for wind onshore, year 2016. On average, the considered maximum capacity factor for the scenarios is of $27 \%$ for wind and of $20 \%$ for solar PV based on measured data for Portugal $[2,20]$.

Fig. 4 illustrates solar and wind onshore intraday complementarity in the data, in all the 4 seasons of the year, through the discernible symmetric variations in the maximum capacity factors values in the intraday time periods considered, which are more pronounced in the case of solar PV compared to wind. This observation is corroborated by the study of the variability and correlation of RES in the Portuguese electrical system presented by Ref. [22] referring to the period 2010-2014. Fig. 4 shows that when solar PV technologies allow the generation of the highest relative amount of electricity, wind is at its least effective availability hours (P4, P5 and P6, ie, from 9 h to $18 \mathrm{~h}$ ). Inversely, when solar technologies are less available, wind is at its highest availability to generate electricity (P7, P8, P1, P2 and P3, ie, from $18 \mathrm{~h}$ to $9 \mathrm{~h}$ ).

\section{Major findings and discussion}

For all the analysed scenarios, Fig. 5 shows the total installed capacity per generation technology in 2020, 2030 and 2050, while Fig. 6 shows the total electricity production per generation technology for the same years.

In Fig. 5 it is clear that the hydro installed capacity is the same in all scenarios, increasing only by 2030 . This is because with the construction of the hydro pump storage exhausts the hydro potential according to the National Hydroelectric Plan. As it can be seen in this Fig. 5, in 2020 and 2030, the investment in both installed solar PV capacity and wind onshore capacity is higher in the "dry" scenario compared to the "humid" scenario, while the installed capacity of natural gas remains the same as in 2016 across all scenarios (no new investments). This should be explained by the lower availability of hydro generation being compensated in the additional capacity in wind and solar, with no particular requirement also for flexibility support. In 2030, in the "reference" and "dry" scenarios including a $\mathrm{CO}_{2}$ cap, the model chooses to install more biomass as well as windoffshore, meaning that, in this period, the system needs to use a generation technology that enables further/increased flexibility to support the constraints imposed to the functioning of the system. Wind offshore is characterized by a higher number of working hours and Biomass is also a more manageable energy source. In 2030, in the "humid" scenario with a $\mathrm{CO}_{2}$ cap, these restrictions are still made available to the system by the hydro technology.

In 2050, natural gas plays a very residual role in each of the scenario. This role, directed towards the balancing of solar PV at off peak hours, is slightly higher in the "dry" scenario than in the "humid" scenario, while there is still a $\mathrm{CO}_{2}$ cap. In 2050, on the other hand, the models goes for investment options in wind

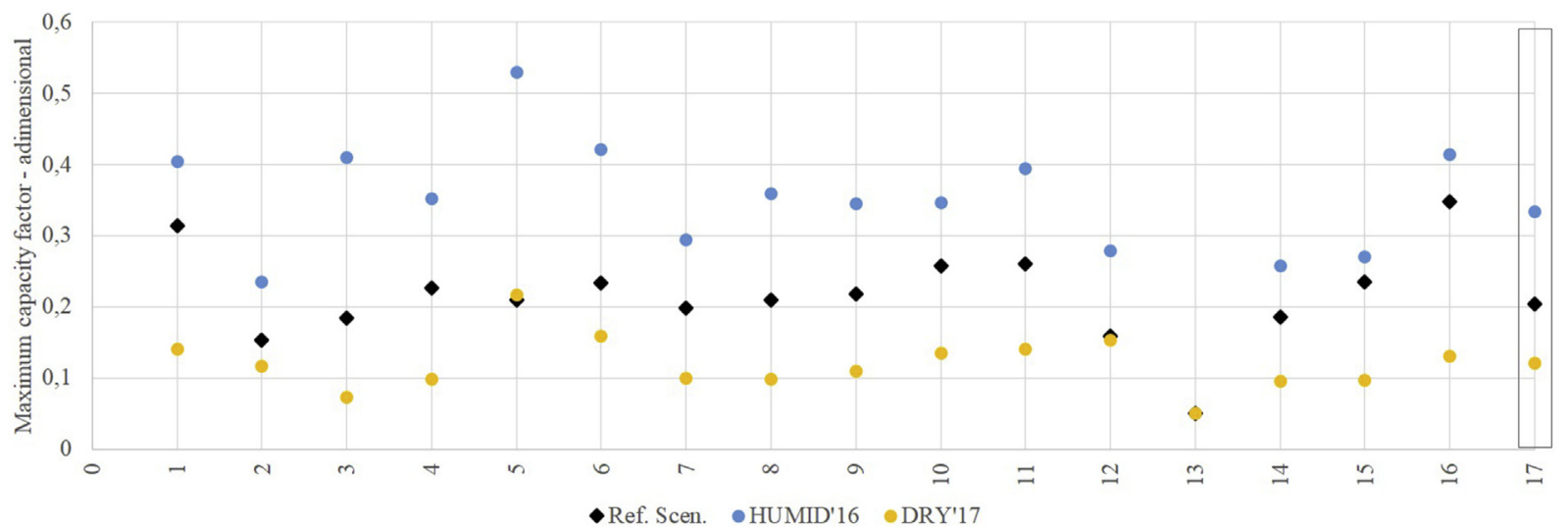

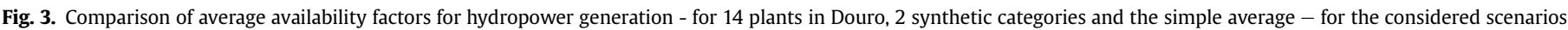
(own calculations based on $[19,20]$ ). 


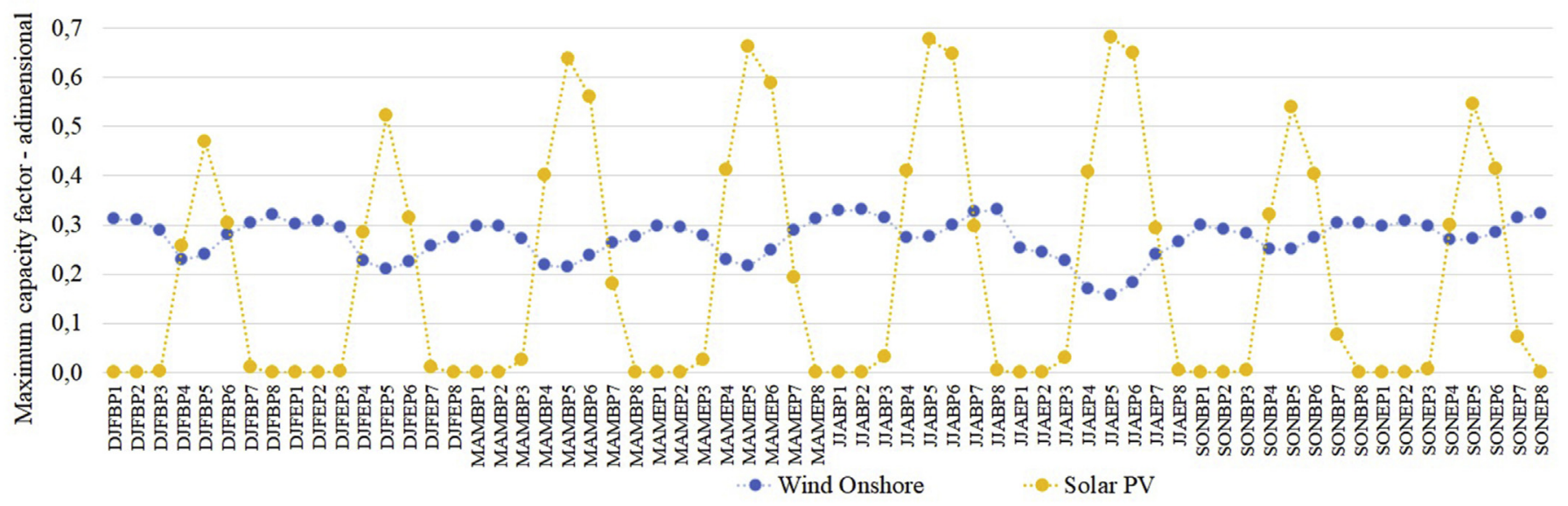

Fig. 4. Maximum capacity factor considered for wind onshore and solar PV in Portugal mainland based on ENTSO-E data [20].

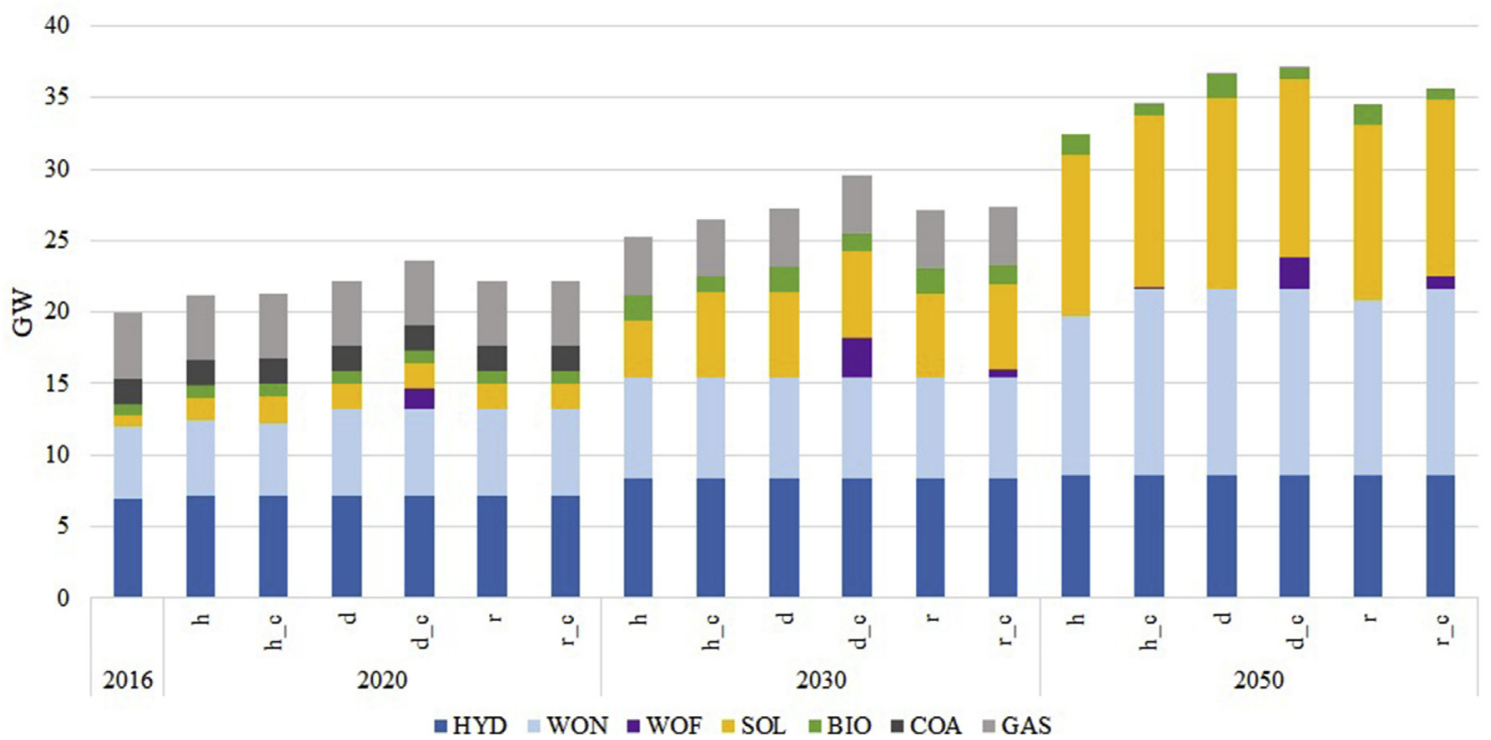

Fig. 5. Installed capacity per generation technology for the considered scenarios in 2020, 2030 and 2050.

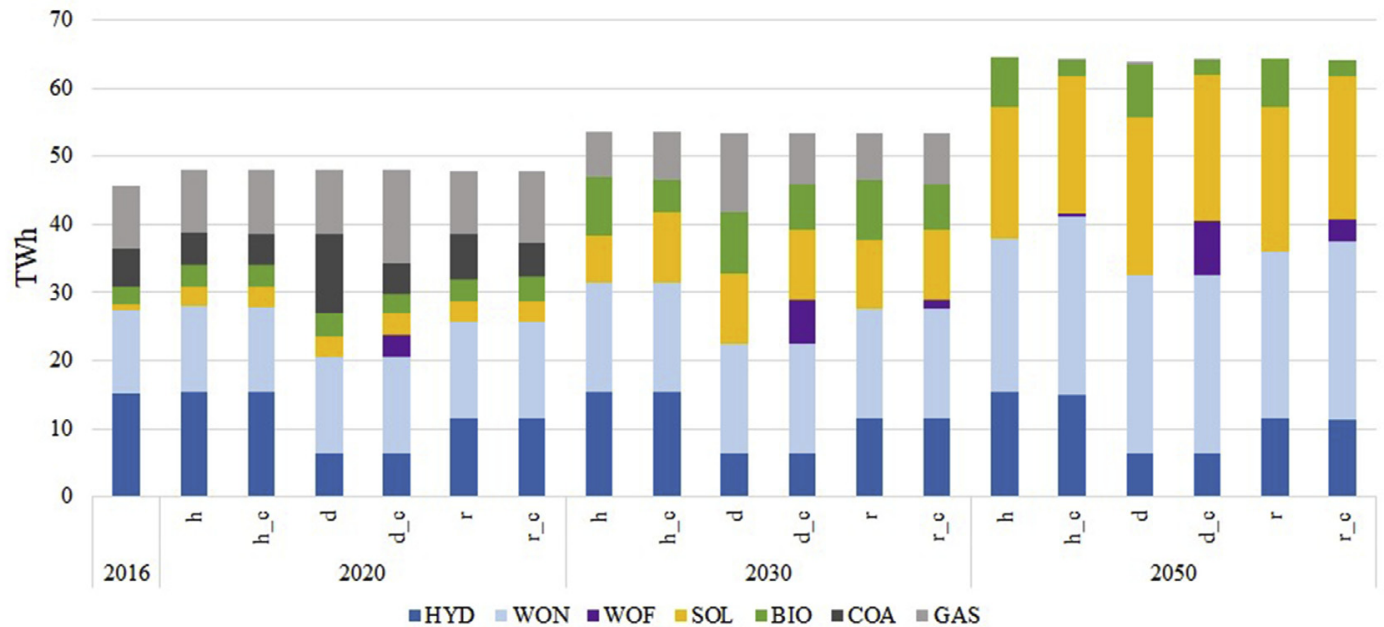

Fig. 6. Electricity production per generation technology for the considered scenarios in 2020, 2030 and 2050. 
onshore, up to its maximum available potential, and in wind offshore in all the $\mathrm{CO}_{2}$ capped scenarios, while in all the uncontrained carbon scenarios the model shows no need for investment in wind offshore. Also, in 2050, solar PV installed capacity is the same in the "dry" and "humid" scenarios. With no $\mathrm{CO}_{2}$ cap, the system also invests in additional biomass compared to $\mathrm{CO}_{2}$ constrained scenarios.

Fig. 6 confirms the impact on operation of the investment options previously shown. In 2020, the less available hydro resource in the "dry" scenario is compensated by more investment in solar PV and some coal generation, also by wind offshore in the "dry" scenario with a $\mathrm{CO}_{2}$ cap. In 2030 and 2050, after the phase-out of coal plants, the use of the available capacity is similar across scenarios for wind and solar PV, and the variability of the hydro resource is managed mostly with the use of biomass and increased $\mathrm{PV}$ generation and, with stringent $\mathrm{CO}_{2}$ emissions restrictions, also increased wind on and offshore.

Below, Fig. 7 shows the \% differences of hydropower generation with respect to the reference case, for a week day, with and without $\mathrm{CO}_{2}$ cap, in each season of 2050 . The hydropower generation variability is higher in the humid than in the dry scenario in Spring, also showing higher variations out of peak hours $(0 \mathrm{~h}-6 \mathrm{~h}$ and $15 \mathrm{~h}-18 \mathrm{~h}$ ). In the remaining seasons, the dry scenarios presents the more significant variations of hydro generation, where out of peak hours are relatively lower than on peak hours $(9 \mathrm{~h}-20 \mathrm{~h})$. The maximum variability is nearly $100 \%$ in a humid scenario and approximately $50 \%$ in a "dry" scenario.

These intraday results are rather knew to the literature, and hence difficult to compare. The reasoning behind these results may be that in circumstances found with low availability of the hydro power (in dry scenario circumstances) the variations in this availability are more important in the time of the day in which solar and wind are not as available off-peak hours, than during daytime hours. These differences may not be as evident in Autumn which is the relatively more humid season in each of the scenarios.

Fig. 8 illustrates the relative differences of all generating technologies between "dry" and "humid" scenarios with respect to the "reference" case, for a weekday, without $\mathrm{CO}_{2}$ cap, in 2050, in Winter (left hand-side) and Spring (right hand-side) in each period of $3 \mathrm{~h}$. In this way, it is perceptible how hydropower variations are being compensated in the whole electricity system in order to satisfy demand.

As depicted above in the Winter (left hand-side), in the "dry" scenario, at off-peak hours of the night $(0 \mathrm{~h}-6 \mathrm{~h})$ lower hydro is compensated by biomass and wind onshore, while at peak-hours $(9 \mathrm{~h}-20 \mathrm{~h})$ mostly with solar PV, biomass and some wind onshore. In the "humid" scenario, from $9 \mathrm{~h}$ to $17 \mathrm{~h}$, the excess hydro replaces solar PV, biomass and wind onshore, while from $0 \mathrm{~h}$ to $9 \mathrm{~h}$ and $21 \mathrm{~h}-0 \mathrm{~h}$ only wind, as there is no solar PV available. In the Spring the variations of hydropower generation in the "humid" scenario are higher, particularly at off-peak hours (P1, P2 and P3) and the use of biomass is compensated. At peak-hour (P6 and P7) windonshore is also very important to manage variability.

The scenarios herein analysed have been compared with those for the electricity sector in the National Roadmap for Neutrality in the "out-of-track" scenario [14,17]. In our futher spatio and temporally discretized eTIMES_PT model, the earlier investment decisions up to 2050 prioritize wind onshore and offshore to solar PV options, and also to new natural gas options in 2050. Similar findings were found in the study [23]. This could be explained by the assumption in this analysis that all variable RES resources are also available to generate electricity to cover peak demand hours. This analysis should be further supported by the analysis of the remaining two socio-economic scenarios addressed in the Roadmap for Carbon Neutrality in 2050.

As far as possible, the results herein presented are compared with the analysis performed by Ref. [9] using the TIMES_PT model, which includes 12 time slices that represent an average day, night and peak demand for every one of the 4 seasons [9]. results confirm hydropower vulnerability to climate change, given that any decrease in water availability induces an immediate decrease in electrical hydropower generation (between $17 \%$ and $41 \%$ ). Our analysis also finds hydropower generation variations near this range, despite more intense (31\% and 63\%) when the system faces decreases in water availability. Our modeling tool, however, looks at variations within the seasons and time of day (as shown in Fig. 7), which, for instance, in 2050, in Winter, are between $31 \%$ and $55 \%$.

Fig. 9 below shows the preferred deployment of installed capacity found for the reference scenario without $\mathrm{CO}_{2}$ cap for wind power generation, on the left hand-side, and for solar PV generation, on the right hand-side, per municipality, in Portugal mainland, which summed to a total of wind of aprox. $12.2 \mathrm{GW}$ and a total of solar PV of aprox. 12.3 GW (Fig. 5). The municipalities with highest wind shares is Arganil and Guarda in the center of the country (with $0.7 \mathrm{GW}$ and $0.6 \mathrm{GW}$, respectively); while with the highest PV installed are Évora and Montemor-o-Novo in the Southern part of the country ( 0.7 and $0.55 \mathrm{GW}$, respectively).

Noteworthy is the possibility of this modeling method to further capture the impacts of variability of resources along time and observe their influence in the transition of the system. This allows better assessing the feasibility of deploying the large capacities of RES based technologies necessary for the transition to a fully

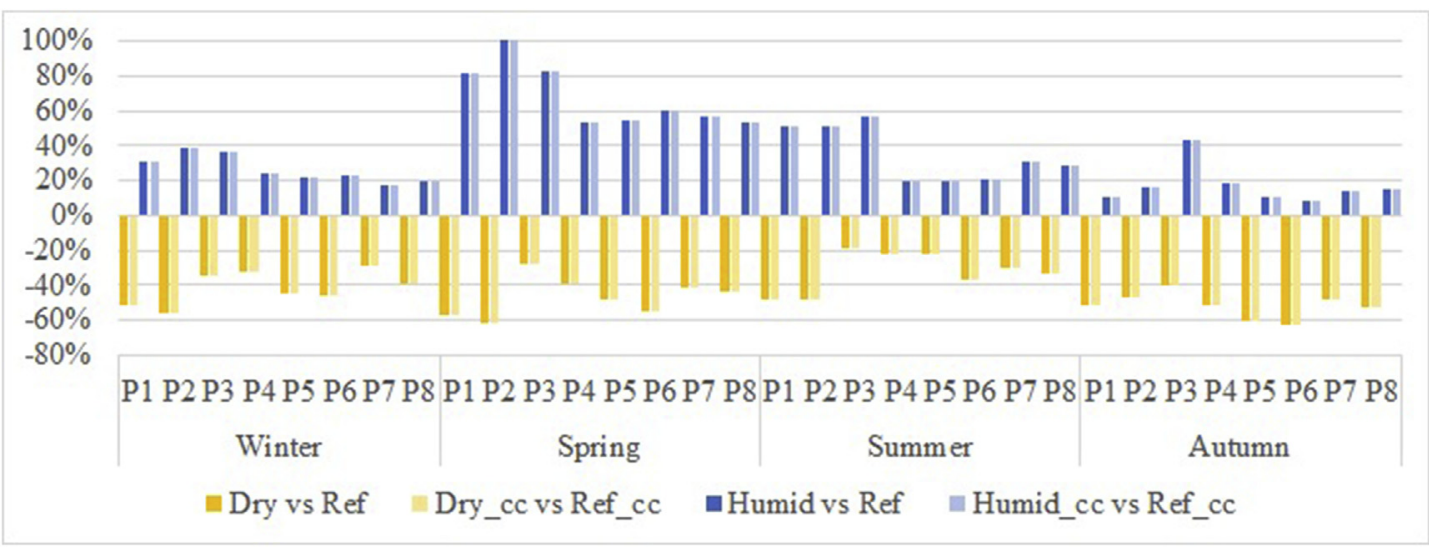

Fig. 7. Variation of hydro generation within a week day, per season, from the dry and humid scenarios in comparison with the reference scenario in 2050. 

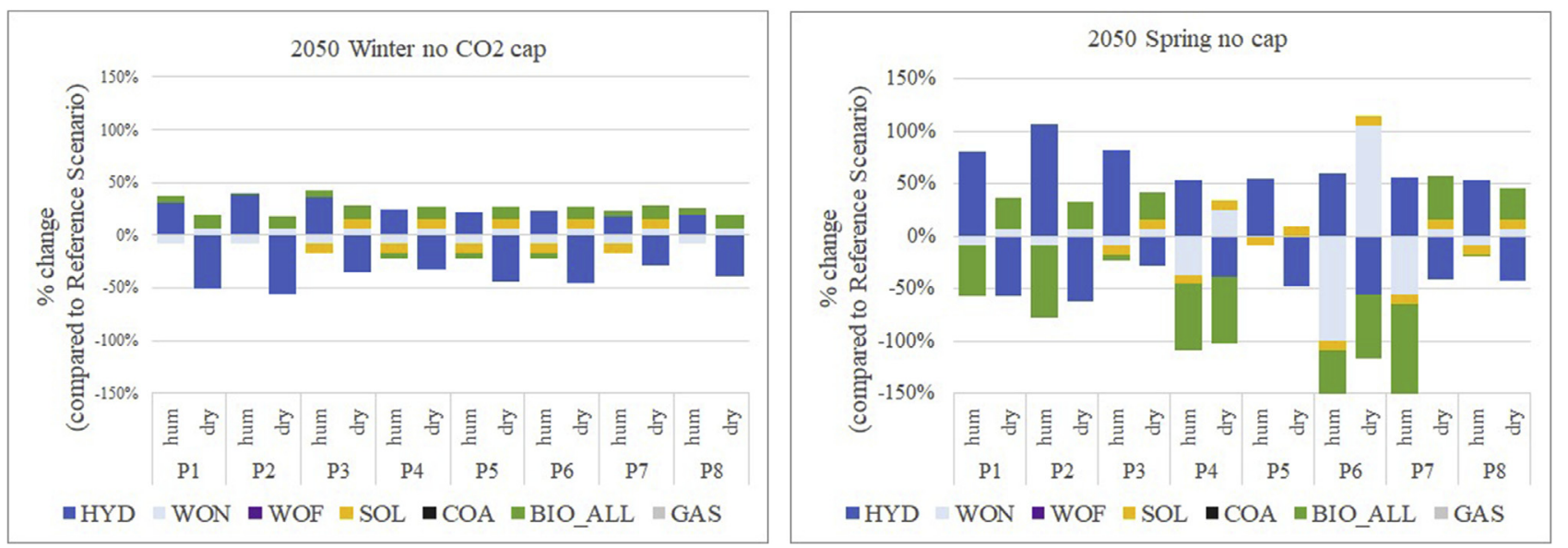

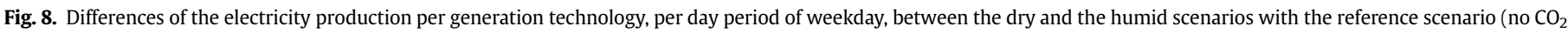
cap) in Winter (left) and Spring (right) in 2050.

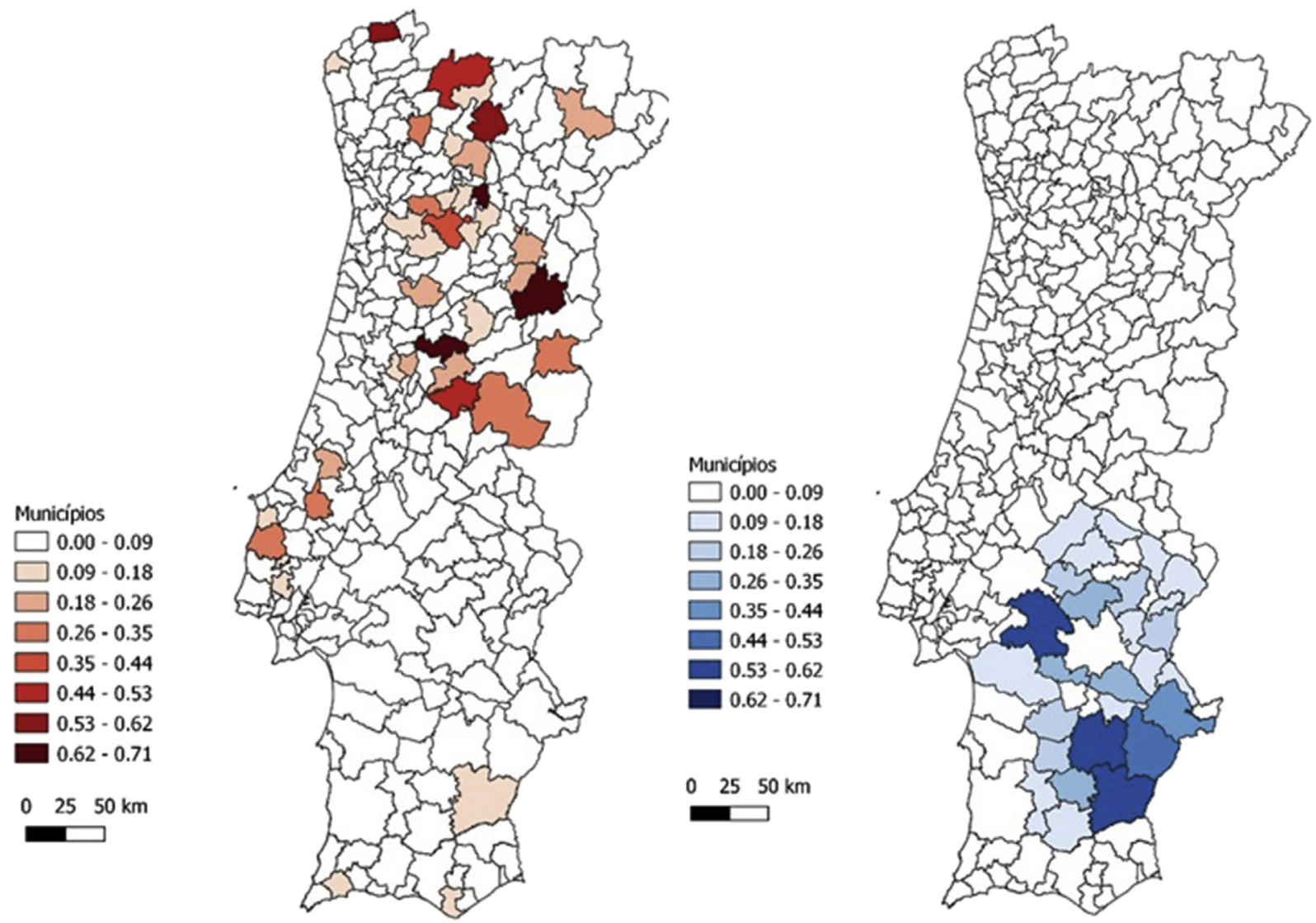

Fig. 9. Deployment of wind (left side) and solar PV (right side), in GW, per municipality in 2050 in the reference scenario without cap.

decarbonised power system.

\section{Conclusions and further research}

This paper presents the ongoing research within the Clim2Power project Portuguese case study. The objective is to assess the relevance of using a highly detailed spatial and temporal modeling tool for studying the future evolution of the power system, considering the needs for integrating large shares of variable RES, namely solar and wind. To do so, we have used the Portuguese power system as a case study. Portugal is an interesting case study due to its current high shares of RES-based electricity: in 2017 which was considered a dry year (below the average by 53\%), the amount of RES generation was $46 \%$ (26\% due to variable RES), while in 2016, which was considered a humid year (above the average by $33 \%$ ) the amount of RES generation achieved 57\% (25\% due to variable RES). Also, Portugal has committed to very ambitious carbon neutrality targets that will lead to a $100 \%$ RES power system by 2050.

We have developed the eTIMES_PT technological optimization 
model, representing the Portuguese power system from 2016 till 2050. Contrarily to previous TIMES models of the Portuguese energy system, which have supported the Portuguese Carbon Neutrality Roadmap published in 2019, the eTIMES_PT model has much higher temporal and spatial detail, considering 64 intrannual time-slices and individual power plants, instead of aggregated types of similar technology plants. To do so, we consider seasonal and intraday hydro, wind and solar resources variability in a large TIMES energy system model. Existing hydro, wind and thermal power plants are modelled individually, whereas new plants are modelled at municipality level.

The impact of introducing climate variability is assessed by modeling six scenarios: a reference case and both "humid" and "dry" hydropower scenarios, complemented with a variant for each that includes additionally a $\mathrm{CO}_{2}$ emissions cap in 2050 of $40 \%$ below 1990 levels. We have found substantial differences in installed capacicity and generated electricity per technology group simply by considering a more spatially and temporally disaggregated model, when compared with previous modeling work using the less disaggregated TIMES_PT model from Ref. [9]. Our results confirm the hydropower vulnerability to climate change, given that any decrease in water availability induces an immediate decrease in electrical hydropower generation (between $17 \%$ and $41 \%$ ). Our analysis also finds hydropower generation variations within this range, despite stronger (31\% and 63\%). Our modeling tool looks at variations within the seasons and time of day which, for instance, in 2050, in Winter, are between $31 \%$ and 55\%. Also, the analysis enables to account for the combined variability of hydro, PV and wind resources. In the future this variability will consider data from seasonal forecasts and from long-term climate projections.

Our results show for Portugal that climate variability may play an significant role in the Portuguese power system. Our next steps are to process the seasonal forecasts and long-term climate scenarios to be run in the eTIMES-PT model. Such a challenge requires combining expertise of climate scientists, statisticians and energy system modellers. This articulation of such a multi-disciplinarity backgrounds entails learning how to communicate between such diverse fields [4].

\section{CRediT authorship contribution statement}

Filipa Amorim: Conceptualization, Methodology, Validation, Writing - original draft, Writing - review \& editing. Sofia G. Simoes: Project administration, Data curation, Writing - review \& editing. Gildas Siggini: Software, Validation. Edi Assoumou: Visualization, Investigation.

\section{Declaration of competing interest}

The authors declare that they have no known competing financial interests or personal relationships that could have appeared to influence the work reported in this paper.

\section{Acknowledgments}

Project CLIM2POWER is part of ERA4CS, an ERA-NET initiated by JPI Climate, and funded by FORMAS (SE), DLR (DE), BMWFW (AT), FCT (PT), EPA (IE), ANR (FR) with co-funding by the European Union (Grant 690462). CENSE is financed by Fundação para a Ciência e Tecnologia, I.P., Portugal (UID/AMB/04085/2019). The authors acknowledge the valuable contributions of colleague Patrícia Fortes from CENSE.

\section{References}

[1] International Energy Agency. Renewables 2018 - market analysis and forecast from 2018 to 2023. IEA; 2018.

[2] REN - Redes Energéticas Nacionais. Dados técnicos 2017. In: Redes energéticas naionais. SGPS, S.A; 2018. http://www.centrodeinformacao.ren.pt/PT/ InformacaoTecnica/DadosTecnicos.

[3] Chandramowli SN, Felder FA. Impact of climate change on electricity systems and markets - a review of models and forecasts. Sustainable Energy Technologies and Assessments. https://doi.org/10.1016/j.seta.2013.11.003; 2014.

[4] Cronin J, Anandarajah G, Dessens O. Climate change impacts on the energy system: a review of trends and gaps. Climatic Change 2018;151(2):79-93. https://doi.org/10.1007/s10584-018-2265-4.

[5] Barstad I, Sorteberg A, Mesquita M, dos S. Present and future offshore wind power potential in northern Europe based on downscaled global climate runs with adjusted SST and sea ice cover. Renew Energy 2012. https://doi.org/ 10.1016/j.renene.2012.02.008.

[6] Devis A, Van Lipzig NPM, Demuzere M. Should future wind speed changes be taken into account in wind farm development? Environ Res Lett 2018. https:// doi.org/10.1088/1748-9326/aabff7.

[7] Jerez S, Tobin I, Vautard R, Montávez JP, López-Romero JM, Thais F, Bartok B, Christensen OB, Colette A, Déqué M, Nikulin G, Kotlarski S, Van Meijgaard E, Teichmann C, Wild M. The impact of climate change on photovoltaic power generation in Europe. Nat Commun 2015. https://doi.org/10.1038/ ncomms10014.

[8] Collins S, Deane JP, Poncelet K, Panos E, Pietzcker RC, Delarue E, Ó Gallachóir BP. Integrating short term variations of the power system into integrated energy system models: a methodological review. In: Renewable and sustainable energy reviews; 2017. https://doi.org/10.1016/ j.rser.2017.03.090.

[9] Teotónio C, Fortes P, Roebeling P, Rodriguez M, Robaina-Alves M. Assessing the impacts of climate change on hydropower generation and the power sector in Portugal: a partial equilibrium approach. In: Renewable and sustainable energy reviews; 2017. https://doi.org/10.1016/j.rser.2017.03.002.

[10] Pina A, Silva C, Ferrão P. Modeling hourly electricity dynamics for policy making in long-term scenarios. Energy Pol 2011. https://doi.org/10.1016/ j.enpol.2011.06.062.

[11] Amorim F, Pina A, Gerbelová H, Pereira da Silva P, Vasconcelos J, Martins V. Electricity decarbonisation pathways for 2050 in Portugal: a TIMES (The Integrated MARKAL-EFOM System) based approach in closed versus open systems modelling. Energy 2014;69:104-12. https://doi.org/10.1016/ j.energy.2014.01.052.

[12] Welder L, Ryberg DS, Kotzur L, Grube T, Robinius M, Stolten D. Spatio-temporal optimization of a future energy system for power-to-hydrogen applications in Germany. Energy 2018;158:1130-49. https://doi.org/10.1016/ j.energy.2018.05.059.

[13] Simoes S, Zeyringer M, Mayr D, Huld T, Nijs W, Schmidt J. Impact of different levels of geographical disaggregation of wind and PV electricity generation in large energy system models: a case study for Austria. Renewable Energy; 2017. https://doi.org/10.1016/j.renene.2016.12.020.

[14] Portuguese Government. Roadmap for cabon neutrality 2050 - long-term strategy for carbon neutrality of the Potuguese economy by 2050. 2019 . https://www.portugal.gov.pt/download-ficheiros/ficheiro.aspx?v=aa27c4c9dac3-47c3-96ae-4ca86183635d.

[15] Loulou R, Remme U, Kanudia A, Lehtila A, Goldstein G. Documentation for the TIMES model Part I. IEA Energy Technology Systems Analysis Programme; 2005.

[16] Nahmmacher P, Schmid E, Hirth L, Knopf B. Carpe diem: a novel approach to select representative days for long-term power system modeling. Energy 2016;112:430-42. https://doi.org/10.1016/j.energy.2016.06.081.

[17] Fortes P, Seixas J, Dias L, Lopes R, Gouveia JP. The mix \& match between stakeholders and energy system modelling towards a carbon neutral economy. In: International energy workshop. IEA; 2019. http://www. internationalenergyworkshop.org.

[18] DGEG. Renováveis - estatísticas rápidas. In: Direção-Geral de Energia e Geologia; 2018. www.dgeg.pt.

[19] EDP Produção. Douro hydropower hourly generation data per powerplant from 2004 to 2017. Energias de Portugal EDP; 2018.

[20] ENSTO-E. ENSTO-E transparency platform. 2020. https://transparency.entsoe. eu/.

[21] Dias L, Gouveia JP, Lourenço P, Seixas J. Interplay between the potential of photovoltaic systems and agricultural land use. Land Use Pol 2019. https:// doi.org/10.1016/j.landusepol.2018.11.036.

[22] Castro R, Crispim J. Variability and correlation of renewable energy sources in the Portuguese electrical system. Energy for Sustainable Development 2018;42:64-76. https://doi.org/10.1016/j.esd.2017.10.005.

[23] Portuguese Renewable Energy Association (APREN);Pöyry. Portuguese market outlook up to 2040 - poyry: a report to apren. 2018.

[24] Simoes Sofia G, Amorim Filipa, Frohlich Kistrina, Ostermoeller Jennifer, SaintDrenan Yves-Marie, Assoumou Edi, et al. Clim2power - translating climate data into power plants operational guidance. In: Proceedings of the 4th International Conference on Energy and Environment, ICEE 2019, Guimaraes, Portugal May 16-17. Book Series: ICEE International Conference on Energy \& Environment; 2019. p. 629-34. https://coutin68.wixsite.com/icee2019. 